\title{
The Comparative Study of Foreign Worker Policy Implementation: The Case Study Of The Three Provinces in The Eastern Part Of Thailand, Srakaew, Chantaburi And Traad
}

\author{
Wichai Jongchotchatchavan,wchaval@gmail.com; \\ Patchanee Taraseina'taraseina@yahoo.com; \\ Ritthikorn Siriprasertchok, ritthikorn@buu.ac.th \\ Graduate School of Public Administration, Burapha University, \\ Chonburi, 20131, Thailand
}

\begin{abstract}
Based on relevant documents and in-depth interview from various authorities, this study reveals four-dimension of findings. Firstly, with regard to foreign worker policy, it is found that the policy'sobjectives and goals of all the three provinces are clear, but the goals and objectives are notsuccessfully reached. The study reflects that such goals and objectives do not stipulate problem alleviation approaches, and also are stillin form of the routine annual shortterm ones. In terms of the policy compliance to achieve the goals, each province complies with the governmental national approach. In addition, the provincial governors are allowed to annex this approach with provincial policy to meet economic demands of each province based on problem-oriented approach. Moreover, the committee from relevant authorities should be established to ease the problem locally. Secondly, with regard to resources, it is found that all the provinces have sufficient financial resources, but are lack of tools, equipment, operating sites, as well as personnel. Thirdly, with regard to the authorities implementing policy, it is found that there are five major direct authorities: the provincial offices of employment, the provincial offices of public health, the provincial immigration offices, the citizen registration offices, and the military authorities. All these parties employ the laws and regulations they are governed individually whichleads to the irrelevancy of the processes. Lastly, as far as circumstancesare concerned, in terms of the economic dimension, border trade there contributes to $80 \%$ of Thai-Cambodian commerce. On the social dimension perspective, as a result of illegal immigration and illegal status, many opportunities and rights of the alien workers are prohibited. Thus, in terms of the political dimension, it has an impact on the foreign worker policy annually.
\end{abstract}

Keywords: political implementation, foreign worker, provincial policy

\section{Introduction}

Thai economy is highly increase due to the significant change from agricultural production to industry and services. Therefore, the country's needs for more labor are obvious. Contradictory, the Thai industrial sector has still been facing with a lack in labor forces. In response to this critical need, the Thai Government has launched a policy on foreign workers from its neighboring countries to alleviate the said problem. (SarochKomkay and Thira Sithammarak, 2009).

The Thai Government has implemented its policy on foreign worker administration by permitting Burmese, Lao and Cambodian workers who have illegally immigrated to temporarily stay and work in the country since B.E. 2535 up till now. The condition stipulated by the government has changed hiring the illegalalien workers to registering them temporarily. In B.E. 2547, the bilateral negotiation with Thailand's neighbors was conducted in order to identify the workers' nationalities - resulting in more channels for legal foreign worker hiring. Between B.E. 2552 - 2555, the government attempted to manage foreign labor systematically - that is to say, the permission for illegal alien workers to be registered and identified about their nationalities leading to foreign worker legalization in Thailand. In addition, other legal measures have been employed to protect, counter and control illegal alien workers. Nevertheless, according to previous foreign worker 
administration measures, it is found that the administration by the Thai Government is not successful as expected on account of inflexible laws and regulations which focus more upon national security than social and economic dimensions resulting in non-conformation to the country's labor demands at present (SarochKomkay and Thira Sithammarak, 2009).

Furthermore, as far as the geography of eastern Thailand is concerned, it borders Cambodia for 789 kilometers with plains, mountains and waterways. Many illegal migrants enter across all of these boundaries - especially border plains to the three provinces in the east of the country; namely Srakaew, Chantaburi, and Traad. Moreover, there is a lack of operating workers in many industrial factories and agricultural sectors; and Cambodian labor capitals are low, so day-time labor hiring is used. Having got paid, several of these workers purchase some goods in Thailand - supporting the economy along with the borders. If, however, these foreign workers are allowed to work without a work permit license, the national security may be challenged in the three dimensions, political, social and economic. (Office of the National Security Council, 2009):

1. Political Dimension: A problem on calling for illegal aliens' status and rights, and pressing on the public sectors; a problem on nationality identification due to non-confirmation of the aliens' nationality by their origin country - causing the difficulties about controlling and reversionto the origin.

2. Social Dimension: Because of illegal immigration, many opportunities and rights of the alien workers are restricted. They may press themselves to struggle for survival, leading to committing crime. Moreover, there is also a birth problem as their descendants' status is not legalized. This may cause a long-term social problem.

3. Economic Dimension: The government may assume more public expenditure since these workers consumes public utilities as well as educational and health services in Thailand, but they pay no tax. In the meantime, as the illegal alien workers usually assume the work the Thais do not prefer to do in particular, they necessarily help drive the Thai economy. As a consequence, seizing them intensively may cause business damage in some sectors.

Under the earlier mentioned limitations and their consequences, the researcher sees that there it is important to seek to understand the Thai government policy implementation accordingly. The comparison of the policy implementation of the three provinces will reflect clearer pictures of the actual practices among them. This will lead to a better understanding of the current situation in term of public policy implementation, from policy to practices.

\section{The Objective Of This Research}

This research aims to compare foreign worker policy implementation in the three provinces in the Eastern Part of Thailand: Srakaew, Chantaburi, and Traad.

\section{Area Of Study}

The research isfocused on the comparison of the Thai Foreign Worker Policy Implementation conducted in the three provinces in the Eastern Part of Thailand bordering Cambodia: Srakaew, Chantaburi, and Traad.

\section{Expected Benefits}

1) The comparison of foreign worker policy implementation in the three provinces in the Eastern Part of Thailand: Srakaew, Chantaburi, and Traad; and

2) The use ofthe research findings as the information for policy-making at the provincial level to conform to foreign worker administrationcircumstances.

\section{Research Methodology}

This descriptive research is conducted using both quantitative and qualitative methods. The quantitative method is done through the questionnaires whereas the qualitative method is administer through includes document analysis and focus groups. Primary information and data were collected from relevant research by several authorities: namely the Office of the Council of State, the Office of the Prime Minister, the Ministry of Labor, the Office of Foreign Worker Administration, the Immigration Office, the Secretariat of the Cabinet, and the Office of the National Economics and Social Development Board. Relevant documents are as follows: newspaper articles, books, research papers, theses, online information, rules and regulations, laws, foreign 
worker-related acts, and in-depth interview from key persons of various authorities with specified issues. Data analysis was conducted through content analysis on relevant documents and the in-depth interview with all parties involved from public, private and people sectors are conducted, as well as other analytical methods such as comparative analysis regarding data qualities or attributes. Combined with the findings from the interview, data were evaluated as the overview of the study.

Descriptive presentation was used according to the objectives of the study - that is to say, to compare foreign worker policy implementation in the three provinces in the Eastern Thailand.

\section{The Research Model}

In this study, the authors used relevant factors from the model of Van Meter and Van Horn, and WoradejChantasornin order to analyze the relationship between the factors and policy implementation. The foreign worker policy is quite costly, and needs to be promoted by both civil society and political sectors. This policy needs respect and cooperation from all practitioners - government officials, entrepreneurs, and employees - because it is associated with their behavioral changes. In this research, the authors thus focused on four factors as follows:

1) Foreign worker policy: The authors considered the clarification of the objectives and goals of the policy, the ability to ease problems, and policy compliance to achieve the goals;

2) Resources: The authors considered financial resources sufficiency, tool and equipment preparedness, and personnel resources sufficiency;

3) Authorities implementing policy: Organization structure, rules and regulations, operating personnel's attitude, and internal communication were considered; and

4) Circumstances: Economic, social, and political circumstances as well as the support from central and local governments were studied.

\section{Findings}

From the comparative study of foreign worker policy implementation: The case study of the three provinces in the Eastern Part of Thailand, Srakaew, Chantaburi, and Traad, the findings are divided into four dimensions are as follows:

\subsection{Foreign Worker Policy:}

1.1) The clarification of the objectives and goals of the policy: It is found that the objectives and goals of the policy of all the three provinces are clear. From the past to the present, both the objectives and goals have been occupation reservation for Thai citizens.

1.2) The ability of the foreign worker policy to ease problems: It is found that it is unable to reach its objectives and goals because it does not stipulate problem alleviation approaches as the following:

1.2.1) With regard to the policy on arresting and pushing out illegal alien workers, it is found that the workers are not actually arrested and pushed out, and the policy is unable to protect and prevent new illegal migration.

1.2.2) With regard to the policy on illegal alien worker registration, it is found that both employers and alien workers do not see beyond any importance of registrations- contributing to unknown demands on labor and exact numbers of foreign workers in Thailand.

1.2.3) With regard to the policy on nationality identification towards alien workers in Thailand, it is found that both employers and alien workers do not pay enough attention due to high cost, and complicated and delayed processes.

1.2.4) With regard to the policy on permitting illegal alien workers to temporarily work in accordance with stipulation of the government during waiting period before returning to their origin countries by the resolution of the Cabinet on permitting and approaching annual illegal alien worker registration, the study finds that it is unable to alleviate foreign worker-related problems obviously and efficiently because there is a decrease in the number of registered foreign workers each year.

1.3) The policy compliance to achieve the goals: All of the three provinces in eastern Thailand - Srakaew, Chantaburi, and Traad - have implemented foreign worker policy. The operating authorities of each province comply with the approach of the national government. In addition, the provincial governors are allowed to annex this approach with provincial policy to meet economic demandsof each province - based on problem-oriented approach. Moreover, the committee from relevant authorities may be established to ease the problem locally; for example, importing foreign agricultural labor to SrakaewProvince through the ChaidanBurapa 
Farmers Association; importing alien labor by Pong Num Ron Model of Chantaburi Province through the Thai-Cambodian Border Tourism and Trade Association; and importing foreign fishery workers through the Traad Fishery Association / the Fishery Labor Center. It is found that the objectives of the policy cannot be reached due to the conformation between the Alien Working Act, B.E. 2551 and the Immigration Act, B.E. 2522.

\subsection{Resources:}

2.1) Financial resources sufficiency: According to the study, it is found that budgeting for foreign workers in each province is related to the number of illegal alien workers. For example, the number of them in Traad is higher than Chantaburi and Srakaew. Traad Province, therefore, has more budgets than the others. However, there was a decline in numbers in Traad in B.E. 2555 - showing that financial resources sufficiency has an impact on the achievement to the policy's objectives.

2.2) Tool, equipment and venue preparedness: all the three provinces are not well-prepared in terms of their tools and equipment such as old-fashioned computers, tools for appearance examination, and data base system. These cannot be used to identify foreign workers correctly. This is an obstacle to function a responsibility.

2.3) Personnel resources sufficiency: the number of operating officials in all of the three provinces is inadequate because the majority of them are temporary employees. The flow of the officials usually happens - causing waste of time and budgets to train the newcomers. Furthermore, some organizations have insufficient officials to meet the demands of service receivers, so the officials have inappropriate workload; for example, Srakaew Immigration Office has faced with this problem as there are a substantial number of migrants holding their border pass cards.

\subsection{Authorities Implementing Policy:}

3.1) Organization structure: five major organizations were studied; namely the Ministry of Labor, the Ministry of Public Health, the Royal Thai Police, the Ministry of Interior, and the Ministry of Defense.

3.2) Rules and regulations of the authorities: each organization employs the rule and regulations which they are under individually - such as the Department Employment, Ministry of Labor, complies with laborrelated laws, for instance, the Alien Working Act,
B.E. 2551; and the Provincial Immigration Offices, Royal Thai Police, complies with the Immigration Act, B.E. 2522, which does not cover current changing situations. To illustrate, there is a disagreement between Article 14 of the Alien Working Act, B.E. 2551 and Article 13 (2) of the Immigration Act, B.E. 2522.

3.3) Operating personnel's attitude: personnel implementing the policy mostly think that the foreign worker policy is not valuable to alleviate foreign worker-related problems, and does not bring about more occupations for Thai citizens. It is generally believed to solve the problem at end consequence.

3.4) Internal communication: each major organization stipulates their procedures for provincial-level authorities. Each province establishes their working groups for foreign workers. This contributes to usual internal communication both formal and informal - such as monthly working group meeting chaired by the governor. Each authority needs to inform their tasks and performance every month, so that they know current situations and approaches at the provincial level.

\subsection{Circumstances}

4.1) Economic circumstance: the geography of the three provinces is suitable as it connects with Cambodia with the plains. Border trade there is $80 \%$ of Thai-Cambodian commerce - especially, trading at the Aranya Pradesh Customs and the Poi Pet Customs, BanteayMeanchey. Thereby, the foreign workers cluster in Srakaew, Chantaburi, and Traad.

4.2) Social circumstance: because of illegal immigration, many opportunities and rights of the alien workers are restricted. They may press themselves to struggle for living, so that many commit a crime. Moreover, there is also a birth problem as their descendants' status is not legalized. It may cause a long-term social problem.

4.3) Political circumstance:there is a direct role of the political sector. The policy is related to permitting illegal alien workers to stay and work in Thailand temporarily - causing that the policy is irrespective and unachievable to implement.

4.4) The support from central and local governments: the foreign worker policy is supported by both central and local governments, as well as the private sector as entrepreneurs who need foreign labor; for instance, - In Srakaew, there is cooperation among the ChaidanBurapa Farmers Association, Srakaew 
Immigration Police, and the Provincial Office of Employment.

- In Chantaburi, there is cooperation among the Chantaburi Marine Corps, Chantaburi Immigration Police, and the Thai-Cambodian Border Tourism and Trade Association.

- In Traad, there is cooperation between Traad Fishery Association / the Fishery Labor Center, and the Provincial Office of Employment.

\section{Suggestion}

1) The provinces should be empowered, and some responsibilities should be decentralized to the provinces to alleviate foreign worker problems in their own areas, because each of them knows their own problems and demands of entrepreneurs for alien workers.

2) Article 14 of the Alien Working Act, B.E. 2551 should be amended to conform to Article 13 (2) of the Immigration Act, B.E. 2522 due to the impact of day-time or seasonal labor hiring in the three provinces.

3) The tools for appearance examination, data registration system, and connecting systemshould be developed in order to identify and examine foreign workers' information and data correctly.

\section{References}

(1) Woradej Chantasorn. 2009.Public Policy Implementation Theory. Bangkok: Sahay Blog and PrintingCo.Ltd.
(2) Saroch Komkay and Thira Sithammarak. 2009. Analyzing Legal Problems on Management of Illegal Alien Workers. April 27, 2009. From URL: $\quad$ http://www.research.rmutt.ac.th/wpcontent/uploads/2012/05pdf.

(3) Internal Security Affairs Bureau. 2010. Border Security.The official conference workshop practice in border area. February 3, 2010. Joint Border and Immigrants Division, Internal Security Affairs Bureau. Department of Provincial Administration.

(4) Office of Foreign Workers Administration 2012.Journal of Statistics Aliens who obtain legal permission to work in Thailand between year 2006 - 2012. June 21, 2012. From URL: http://wp.doe.go.th/joomla_wp/images/statistic/sy /sy2555.pdf

(5) Office of the National Security Council, 2009.Documents on the Preparation of the Strategy Solution Illegal Alien Workers. KP Grand Hotel, Chanthaburi. April 24, 2009.

(6) Anderson, J. E. Public Policy-making.Greata Britain: Thomas Nelson and Sons Ltd., 1975.

(7) Esward, G.C. III, Implementing Public Policy. Washington, D.C. : Congressional Quarterly Press, 1983.

(8) Kerrs, Donna H. The Logic of Policy and Successful Policy. Policy Science 7 (1976): 351363 